\title{
Botulinum Neurotoxins
}

\author{
Robert P. Webb ${ }^{1}$, Virginia I. Roxas-Duncan ${ }^{1}$ and Leonard A. Smith ${ }^{2}$ \\ ${ }^{1}$ Integrated Toxicology Division, \\ US Army Medical Research Institute of Infectious Diseases, \\ ${ }^{2}$ Senior Research Scientist (ST) for Medical Countermeasures Technology, \\ Office of Chief Scientist, \\ US Army Medical Research Institute of Infectious Diseases, Frederick,
}

USA

\section{Introduction}

Botulism is a neuroparalytic disease caused by neurotoxin produced from the bacterium Clostridium botulinum. The botulinum neurotoxins (BoNTs) are among the most potent known biological toxins and have an estimated human median lethal dose $\left(\mathrm{LD}_{50}\right)$ in the nanogram/kilogram range. Botulinum toxins have historically been employed as biological weapons (BW) through state-sponsored programs in Japan, Germany, the United States, Russia and Iraq as well as by independent terrorist organizations. The extreme potency of the toxin, its persistence within affected neurons, the need for protracted intensive care, and the lack of an effective post-intoxication therapeutic intervention make BoNTs a potentially deadly offensive biological weapon.

\section{Botulinum neurotoxins as biological weapons}

\subsection{Historical applications of botulinum toxins in biological warfare}

There have been reports of botulinum neurotoxin being used as an offensive weapon since the early 1900s. Anecdotal accounts describe the implementation of crude anaerobic fermenters made by burying canteens filled with water, green beans and slivers of meat to facilitate C. botulinum production for use against Mexican federal troops in 1910 (Carrus, 2001). Documented state sponsored programs utilizing BoNT as a potential BW were reported as early as the 1930s when the military medical commander of Unit 731, General Shiro Ishii, confessed to feeding food contaminated with lethal cultures of $C$. botulinum to prisoners of war (Williams \& Wallace, 1989). In the early 1940s, the US developed a BoNTbased BW program in response to Allied intelligence reports that Germany was attempting to develop the neurotoxin as an offensive weapon to be used against an invasion force (Franz et al., 1997). The initial efforts of the US program were primarily directed at the isolation and purification of the toxin and the elucidation of the mechanism of pathogenicty of BoNT, then referred to as agent " $X$ " (Cochrane, 1947). In response to the potential threat from Germany, over 1 million doses of a botulinum toxoid vaccine were prepared for Allied troops involved in the D-Day invasion in Normandy (Bryden, 1989). The 1972 Convention on the Prohibition of the Development, Production, and Stockpiling of Bacteriological 
(Biological) and Toxin Weapons and on their Destruction signed by President Richard M. Nixon went into effect in March of 1975, effectively terminating the US BW efforts. All of the biological agent stockpiles created in the US offensive program, including botulinum neurotoxins, were destroyed. Despite being signatories on the convention, the Soviet Union continued not only to pursue its biowarfare program, including research on botulinum neurotoxins, but expanded their program during the post-Soviet era (UNSC, 1995; Bozheyeva et al., 1999). Botulinum toxins were reportedly one of several biological agents tested at the Soviet Aralsk-7 site on Vozrozhdeniye (Renaissance) Island in the Aral Sea. The Soviets were also believed to have attempted to use recombinant DNA technology to introduce BoNT genes into alternative strains of bacteria for the purpose of enhancing toxin production (Alibek \& Handleman, 1999). Iraq, which also ratified the 1975 convention, reportedly also significantly expanded its biological weapons program (UNSC, 1995). After the Persian Gulf War, Iraq admitted to a United Nations Special Commission inspection team that approximately 4,900 gallons of concentrated botulinum neurotoxins had been produced for use in specially designed bombs, missiles and tank dispersion instruments in 1989 (Zilinskas, 1997). Iraq maintains that no biological weapons were employed during the Persian Gulf War or Operation Iraqi Freedom and that its stockpiles have since been destroyed (Blix, 2004).

The Japanese cult Aum Shrinkyo (now referred to as Aleph) attempted to develop both chemical and biological weapons after its political aspirations were defeated in the 1990 Japanese Diet elections. Formed in 1987 by Shoko Asahara, this group developed rapidly and was reported to have 50,000 members and over US\$ 1 billion in financial resources by 1995 (Sugishima, 2003). The Aum executed a deadly sarin nerve gas attack in Matsumoto City on June 27, 1994 which killed seven people. On March 20, 1995 they perpetrated a sarin gas assault on a Tokyo subway which killed 12 people and injured over 1000 individuals. Less than a month later they attempted a cyanide gas release in a restroom of the subway's Shinjuku Station. Senior Aum members obtained soil samples in an attempt to isolate toxinproducing strains of $C$. botulinum. Despite the cult having members with a variety of scientific expertise, they are believed to have experienced difficulty cultivating toxigenic strains of $C$. botulinum and were most likely unable to produce any substantial amount of toxin (Sugishima, 2003; Leitenberg, 1999).

\subsection{Domestic threat targets}

The possibility of dissemination of toxins such as BoNT through municipal water supplies or centralized agricultural or food distribution hubs has been explored in a number of scenarios. There has never been a confirmed case of waterborne botulism. In 1980, Notermans \& Havelaar reported on the stability of BoNT/A, / B and / E when introduced into samples of reservoir surface water, drinking water prepared by sand-filtration, and sterile distilled water. Toxicity was reduced $99 \%$ in just over 3 days in the surface water, 9 days in filtered water and relatively stable in sterile distilled water. Treatment with $\mathrm{FeCl}_{3}$, a common coagulant processing step employed in municipal water treatments to remove iron, removed $75-95 \%$ of the toxins. Treatment with $1 \mathrm{mg}$ of ozone per liter for $2 \mathrm{~min}$ destroyed $\geq 99 \%$ of the toxins and $0.3-0.5 \mathrm{mg} / \mathrm{L}$ sodium hypochlorite ablated $99 \%$ of the toxicity in 30 seconds. Despite the extreme potency of BoNTs, their application as a bioterrorism weapon by introduction into a water supply in the US would most likely be 
unsuccessful when conventional municipal water treatment methods are employed (Notermans \& Havelaar, 1980; Wannemacher, at al., 1993). Another consideration is that large-capacity reservoirs undergo a relatively slow turn-over rate and so a comparably large inoculum of botulinum toxin would be needed (Burrows et al., 1997). Given the technical difficulties involved in producing such a large amount of toxin, this route seems unlikely. Small-scale (personal-use) water filtration systems utilizing ceramic or membrane filters with a 0.2 to $0.4 \mu \mathrm{m}$ pore size were found to be insufficient to effectively remove BoNT/B introduced into drinking water. However, a reverse osmosis device was found to remove BoNT levels below the detection limit of the mouse bioassay (Hörman, et al. 2005).

American agriculture has been described as being "concentrated, highly accessible, vertically integrated" and as such, susceptible to the malicious introduction of biological toxins or human pathogens at processing or distribution points that would reach consumers before a significant threat was realized (Parker, 2002). Wein and Liu published a mathematical model to predict the effects of the deliberate introduction of botulinum toxin at various points through the nine-stage milk collection, processing and distribution network in the US, as it is associated with a single processing facility (Wein and Liu 2005). The study has a number of variables such as the amount of toxin employed, the total volume of the milk, the specific effect of the pasteurization process on the toxin and variable delivery time and consumptions rates, but all scenarios support a significant outbreak of up to 100,000 individuals. The report generated considerable controversy but the editors of the publishing journal defended the release, citing its potential contribution to developing defensive counter-measures as well as informing federal and state governments of the putative threat (Alberts, 2005). The devastating potential of an intentional bioterrorism attack using this avenue was illustrated in 1985 when almost 200,000 people were infected with an antibiotic-resistant strain of Salmonella caused by an inadvertent contamination at a single northern Illinois dairy processing plant (Ryan, et al., 1987).

The potential susceptibility of centralized food distribution platforms in the US can be illustrated by outbreaks attributed to improper processing of mass distributed consumable products. In September 2006, a total of 6 individuals from 2 US states and 1 Canadian province were admitted to local hospitals with cranial neuropathies and flaccid paralysis necessitating mechanical ventilation (CDC, 2007). All of the individuals tested positive for BoNT/A and one patient eventually died. The outbreaks were traced to a commercially produced carrot juice manufactured in a single plant which was distributed under three different brand labels. The intoxications were attributed to a lapse in refrigeration during transport or storage and a lack of chemical barriers to $C$. botulinum germination during processing. In the summer of 2007, 8 cases of botulism in 3 US states led to a massive recall of canned meat products. The outbreaks were traced to product from a single production line in a single plant that was packaged and distributed under 90 different labels (NCFPD, 2008) and which necessitated the recall of tens of millions of cans of suspect food. While these outbreaks represent unintentional distribution of BoNT, they do reveal the complexity of the food production and distribution network in the US and how it might be compromised by a BW attack using a potent toxin such as BoNT. 


\section{Microbiology and BoNT toxicity}

\subsection{The organism and its toxins}

Clostridium spp. are gram-positive, spore-forming, obligate anaerobic bacteria that are ubiquitous in soil and both freshwater and marine sediment (Dunbar, 1990) . BoNTs are produced primarily in C. botulinum but may also be produced in the closely related $C$. butyricum, C. baratii and C. argentinense (Hatheway, 1993). C. botulinum strains are classified into four groups (denoted I to IV) based on metabolic activity (Hatheway, 1988) and genetic composition (Collins, 1998; Hill et al., 2007). Group I includes type A strains and proteolytic strains of types B and F; Group II includes type E strains and nonproteolytic strains of types B and F; Group III includes nonproteolytic strains of types $\mathrm{C}$ and D; and Group IV includes only strains that produce type G. There are seven immunologically distinct serotypes of BoNTs designated by the letters A through G (BoNT/A to BoNT/G) (Smith \& Sugiyama, 1988). BoNT/A, based on animal studies, has a lethal human dose $\left(\mathrm{LD}_{50}\right)$, assuming $70 \mathrm{~kg}$ weight, of approximately $0.09-0.15 \mu \mathrm{g}$ by intravenous administration, $0.7-0.9 \mu \mathrm{g}$ by inhalation, and $70 \mu \mathrm{g}$ by oral administration (Scott \& Suzuki, 1988; Arnon et al., 2001). The toxicity for other serotypes is unknown but all have been shown to uniformly fatal in animals studies. Human botulism is caused primarily by BoNT/A, /B and /E (Arnon et al., 2001), and rarely by BoNT/F (Barash et al., 2005; Gupta et al., 2005). BoNT/C and /D primarily cause botulism in animals. BoNT/G, produced by $C$. argentinense, has been associated with sudden death but not neuroparalytic illness in a few patients in Switzerland (Sonnabend et al., 1981). All seven serotypes can cause inhalational botulism in primates (Middlebrook \& Franz, 1997). Recent characterization of an increasing number of unique BoNT subtypes has revealed small to significant variations at the amino acid level (Smith, et al., 2005; Hill, et al. 2007; Smith, et al., 2007). These variations impact binding and protection of neutralizing antibodies (Smith, et al., 2005) and raise concerns that they may prove problematic to the development of prophylactic and therapeutic agents developed against a dissimilar subtype.

BoNTs are produced as a part of a protein complex in which the toxin is non-covalently bound to two or more protein components. This includes the well characterized hemagglutinins (HA) and a nontoxin, nonhemagglutinin (NTNH). The complexes can be distinguished on the basis of their size and serotype association and include the $\mathrm{M}-(300 \mathrm{kDa}$ in types A-F), L-(500 kDa in serotypes A, B, C, D and G) and LL-(900 kDa in serotype A) forms (Collins \& East, 1988). Although neither accessory protein has been implicated in the toxin-mediated blockade of neurotransmitter release, they are believed to protect the toxin against the harsh environment of the gastro-intestinal tract (Simpson, 2004). The neurotoxin is initially produced as a $150-\mathrm{kDa}$ single-chain protoxin that is proteolytically cleaved into an N-terminal 50-kDa light chain (LC) and a C-terminal 100-kDa heavy chain (HC) di-chain that is linked by a single disulfide bond (DasGupta, 1989). The BoNT HC is further delineated into two domains; the N-fragment or translocation domain ( $\mathrm{Hn})$ and the Cfragment or receptor-binding domain $(\mathrm{Hc})$. These three domains mediate intoxication of the neuron in a defined tripartite mechanism. The toxin is introduced into the nerve cell by receptor-mediated endocytosis through binding of the Hc domain to specific ectoreceptors on peripheral cholinergic nerve cells (Dong et al., 2006; Rummel et al., 2007). The acidic pH of the endosome initiates a conformation change in the dichain toxin that results in the $\mathrm{Hn}$ 
forming a protein channel that facilitates the translocation of the LC out of the endosomal lumen and into the cytosol. The LC is a zinc-containing endopeptidase that target SNARE (soluble $\mathrm{N}$-ethylmaleamide sensitive factor attachment protein receptors) proteins that form the synaptonemal fusion complex in a serotype dependent fashion. The SNARE protein SNAP-25 (synaptosomal-associated protein of $25 \mathrm{kDa}$ ) is cleaved at different sites by BoNT/A, /C, and /E, synaptobrevin (also referred to as VAMP; vesicle-associated membrane protein), is cleaved at different sites by BoNT/B, /D, /F, and /G, and syntaxin is cleaved by BoNT/C (Simpson, 2004). Proteolytic cleavage of SNARE proteins prevents the release of acetylcholine across the synaptic cleft of the neuromuscular junction, resulting in a flaccid muscle paralysis which is the primary clinical sign of botulism.

\subsection{Epidemiology}

Botulism is typically reported in four clinical categories. Foodborne botulism is caused by the ingestion of the pre-formed toxin in contaminated food (CDC, 1998). Most outbreaks are associated with home-canned foods in which inadequate processing results in C. botulinum spores germinating, reproducing and producing the toxin (Shapiro, et al., 1998). These conditions include an anaerobic environment with temperatures ranging from $4^{\circ} \mathrm{C}$ to $40^{\circ} \mathrm{C}$, a $\mathrm{pH}$ range from 4.6 to 7.0, and water activity greater than 0.94 (aw is intensity with which water associates with various non-aqueous constituents and solids) (Baird-Parker \& Freame, 1967; Stringer, et al., 2005). Despite increased educational awareness of the non-permissive conditions for food preparation, foodborne botulism remains a persistent threat. There were, on average, approximately 24 reported cases per year from 1900-2000, but there have been a smaller number of cases (average of 18 year) reported from 2001-2009 (CDC-NBS). In the period from 1950-1996, there were 444 outbreaks in which one or more cases of botulism from a contaminated food source was implicated. Of these outbreaks, $37.6 \%$ were caused by type $\mathrm{A}, 13.7 \%$ by type $\mathrm{B}, 15.1 \%$ by type $\mathrm{E}$ and $0.7 \%$ by type $\mathrm{F}$ while $32.9 \%$ of the incidents were caused by unidentified serotype(s) (CDC, 1998). Improvements in both differential diagnostic methods and the technology utilized in serotyping have resulted in a decrease in unidentified serotypes. In the United Stated from 1990-2000 BoNT/A was responsible for $50 \%$ of all cases of botulism, where types B and E were responsible for $10 \%$ and $37 \%$ of the intoxications, respectively; only $3.6 \%$ of the cases were from an unidentified strain (CDC, 1998).

Infant botulism is a toxicoinfection caused by inhalation or ingestion of clostridial spores that can colonize and produce toxin in the intestinal tract of infants less than 12 months of age (Shapiro, 1998). The ability of the bacteria to thrive and elicit toxin is thought to be attributed in part to a deficiency in protective gastrointesintal bacterial flora and the relatively low levels of inhibitory bile-aid found in children under 12 months (CDC, 1998). This form of the disease was officially recognized in a 1976 report in which two infants presenting with acute infantile hypotonoia and weakness were diagnosed with botulism (Pickett, et al., 1976). This has been the most commonly reported form of the disease in the United States since 1980, with an average of approximately 80-100 cases confirmed annually (Shapiro, 1998). In the US between 1976 and 1996, there were 1442 individual cases of infant botulism reported to the CDC (CDC, 1998). Of these, $46.5 \%$ were caused by type A, $51.9 \%$ by type B. Interestingly, the incidence of infant botulism in the US has a geographical component with $47.6 \%$ of the reported cases occurring in California with Delaware, Hawaii, 
and Utah also experiencing high incidence (CDC, 1988). The correlation between the increased incidences of infant botulism outbreaks associated with certain geographical locations has not been elucidated.

Wound botulism (WB) results from the growth of C. botulinum spores in a contaminated wound with in vivo toxin production. This form of the disease was first reported in 1951 as a relatively rare illness associated with post-operative complications (Davis et al., 1951). Historically, approximately $75 \%$ of the wound botulism cases in the US have been reported in California (Weber, et al., 1993) and this represents over $90 \%$ of the reported incidences in the world (Benson, 2001). There were 127 cases of wound botulism in California from 1951 to 1998. Of these, 105 were attributed to intravenous drug users and all but one were admitted black-tar heroin users (Benson, 2001). The increased incidence of WB in California has not abated and between 1993 and 2006 an additional 17 cases were identified in intravenous drug users; 16 of which were diagnosed with one or more recurrent episodes (Yuan et al., 2011).

Adult intestinal toxemia botulism is a rare toxicoinfection that occurs in older children and adults with abnormal gastrointestinal tract physiology, such as colitis or intestinal surgical procedures (Freeman et al., 1986; Fenecia et al., 1999). The disease has also been correlated with alteration of protective endogenous microflora by broad-spectrum antibiotics after inflammatory intestinal disease or surgery (Chia et al., 1986).

In addition to the four naturally occurring forms of the disease described previously, there are two additional forms of inadvertent botulism that result from the application of the purified toxin. Iatrogenic botulism results from the injection of BoNT for either cosmetic or therapeutic purposes. Two adult patients developed symptoms of botulism when given therapeutic doses of BoNT/A drawn from two different production lots (Bakheit, 1997). These cases have since been attributed to either patient sensitivity to the drug or the inadvertent injection of the toxin directly into the vascular capillaries. An adolescent being treated for spastic quadriparesis with Myobloc (botulinum toxin serotype B) developed clinical signs of a systemic BoNT injection (Partikian, 2007). While there are no clear dosing guidelines for BoNT formulations for therapeutic interventions in children, the clinical diagnosis of botulism was again believed to have been the result of inadvertent injection into a blood vessel or diffusion from nearby muscle sites. In November of 2007, four adults were given cosmetic injections of undiluted BoNT/A intended for laboratory research (Chertow et al., 2006). Serial dilutions of two of the individual's serum samples indicated they were given approximately 21 to 43 estimated human lethal doses. All four patients survived but only after prolonged hospitalization with anti-toxin treatment and ventilator support ranging from 40 to 104 days.

Inhalational botulism is intoxication by an inhalational exposure of the aerosolized toxin. The only reported human inhalation incidence occurred in Germany in 1962 during a necropsy when three laboratory workers were exposed to animals subjected to aerosolization of a highly purified, lyophilized BoNT/A (Holzer, 1962). The patients were hospitalized five days postexposure, administered equine antitoxin, and discharged after 9 days. While not a naturally occurring form of the disease, inhalational botulism has implications as a potential weapon of bioterrorism (Middlebrook \& Franz 1997; Zilinskas, 1997). An aerosol dispersion of BoNT could create a toxic gas cloud that could encompass a large area and is considered to be a likely scenario for a terrorism attack. 


\subsection{Clinical symptoms}

The clinical presentation of botulism is characterized by distinctive neurological symptoms of the voluntary motor and autonomic cholinergic-associated junctions in the infant, wound and intestinal forms of the disease (CDC, 1998). Foodborne botulism is often accompanied by acute gastrointestinal distress including nausea, abdominal cramps, vomiting and diarrhea that precede the neurological symptoms (Hughes et al, 1981), particularly in types $\mathrm{B}$ and E. The initial symptoms of food botulism can manifest anywhere from within a few hours to several days postintoxication. The time to onset of symptoms, the severity and the duration of the disease is largely dictated by the exposure dose and the serotype (Arnon, 2001; Woodruff et al., 1992). Infant botulism may present with constipation, poor feeding, diminished suckling, neck and peripheral weakness, weak crying increased drooling (Corblath, et al., 1993) and ventilatory failure (Arnon, 1992; Long et al., 1985). Wound botulism does not display the gastrointestinal symptoms observed in the foodborne form. Fever, if present, is generally attributed to a wound infection rather than botulism.

The neuroparalytic effects of botulism present as an acute, afebrile, descending, bilateral flaccid paralysis. The initial neurological symptoms generally involve cranial nerves III, IV and VI (Sobel, 2005) and include ocular disorders such as blurred vision, diplopia, ptosis and photophobia (Terranova et al., 1979). This is generally followed by dysfunction of cranial nerves VII and IX which cause, dysphagia, dysphonia and dysarthia. The neurological impairment may then spread to the upper extremities, the trunk and then the lower extremities. Respiratory distress can be caused by a weakened glottis that tends to obstruct the airway during attempted inspiration or from paralytic weakness of the diaphragm and parasternal and intercostas muscles. Fatigue, sore throat, dry mouth, constipation and dizziness have also been reported to be associated with botulinum intoxications (Hughes, 1981). Fatalities are most often the result of respiratory failure or secondary infections typically associated with prolonged mechanical ventilation. Bleck summarized the clinical findings of several published reports of foodborne botulism by symptom and serotype as shown in Table 1 (Bleck, 2000).

The primary neurological disorders associated with botulism are common to the foodborne, intestinal, and wound forms of the disease (Sobel, 2005). The duration and severity of the neuroparalytic effects of the disease can be influenced by both the amount and serotype of the toxin introduced into the system. Insight into the impact of the different serotypes in humans has only recently been investigated and much of the data comes from studies involving the therapeutic applications of BoNTs. Of the three most prevalent serotypes involved in human incidences of botulism, BoNT/A has been shown to have the most persistent action and can last 12-16 weeks when used in therapeutic applications (Eleopra, 2004). Serotype B has also been used in therapeutic applications but only exhibits the comparable efficacy to BoNT/A when used in higher doses (Sloop, et al., 1997; Settler, 2001). Electrophysiological studies conducted in juvenile monkeys using purified BoNT/A (BOTOX, Allergan, Irvine, CA) and BoNT/B (Neurobloc, Elan, Shannon, Ireland) indicated BoNT/A diffusion was more pronounced (Arezzo, 2001). The few studies pertaining to serotype C in humans (Eleopra et al., 1997; Eleopra et al., 1998a, Eleopra et al., 1998b) indicate that it is similar to BoNT/A in terms of the toxicity and duration of activity. A 2004 study evaluated the electrophysical responses to human volunteers injected with low doses 
Type A (\%) Type B (\%) Type E (\%)

Neurological symptoms

Dysphagia

$\begin{array}{lll}96 & 97 & 82\end{array}$

Dry mouth

83

100

93

Diplopia

90

92

39

Dysarthia

100

$69 \quad 50$

Upper extremity weakness

86

76

64 NA

Lower extremity weakness

64

NA

Blurred vision

100

91

Dyspnea

91

42

88

Paresthesiae

20

34

NA

Gastrointestinal Symptoms

Constipation

Nausea

Vomiting

Abdominal cramps

Diarrhea

$\begin{array}{ll}57 & 96\end{array}$

Miscellaneous symptoms

Fatigue

Sore throat

Dizziness

$30 \quad 63$

Neurological Findings

Ptosis

Diminished gag reflex

Ophthalmoparesis

46 NA

Facial paresis

Tongue weakness

Pupils fixed or dilated

Nystagmus

Upper extremity weakness

Lower extremity weakness

DTRs diminished or absent

Initial mental status

Alert

473

DTRs, deep tendon reflexes; NA, not available.

Table 1. Summary of Symptoms of Patients with Botulism Caused by Serotypes A, B an E. from Springer Scientific Publishing. 
of BoNT/A, /B, /C or /F (Eleopra et al., 2004). The results were consistent with other research efforts in that BoNT/B, used in higher doses, and BoNT/C have a similar profile as BoNT/A. As reported in previous studies (Mezaki et al., 1995; Chen et al., 1998), BoNT/F was found to have a shorter duration compared to BoNT/A.

\subsection{Diagnosis of botulism}

A rapid and accurate identification of botulism is not difficult when the disease is strongly suspected, such as found in the setting of a large outbreak. But because cases of naturally occurring botulism most often occur singularly, the individual diagnosis may prove more challenging. Botulism is thought to be substantially underdiagnosed (CDC, 1988) and with low-level exposure, minor neurological manifestations of the disease may resolve without medical intervention. A differential diagnosis of botulism without concurrent knowledge of a confirmed outbreak can be difficult and other paralytic illnesses may need to be excluded. These include Guillain-Barre syndrome, myasthenia gravis, tick paralysis, and EatonLambert syndrome (Dembek, et al., 2007). Less likely conditions such as tetrodotoxin and shellfish poisoning, aminoglycoside toxicity and a variety of other neurotoxic products and neurological abnormalities may initially present with similar symptoms. However, a thorough medical examination of the patient and their medical history can generally exclude any competing diagnosis. A patient presenting with an acute, bilateral, descending flaccid paralysis that is afebrile and has normal sensorium should suggest a clinical case of botulism.

The most reliable method for the detection of BoNTs and for diagnosing botulism is the mouse bioassay. This test can be performed by the Centers for Disease Control and Prevention (CDC) or state public health laboratories. The assay involves injecting mice with samples collected from patients displaying symptoms of botulism. Mice will typically begin showing signs of botulism within $8 \mathrm{~h}$. The serotype of samples can also be ascertained in this manner by neutralizing the toxin with serotype-specific antibodies prior to injecting the mice (Shapiro et al., 1998). In cases of foodborne or infant botulism, stool samples can also be cultured to look for C. botulinum. Samples of the suspected food should also be cultured anaerobically with heat or alcohol treatment to select for spores.

\section{Medical countermeasures}

\subsection{Current medical intervention}

Standard therapy for botulism involves administration of botulinum antitoxin in an attempt to prevent neurologic progression of a moderately progressive illness, or to reduce the duration of respiratory failure in individuals with a severe, rapidly progressive illness. This is done in conjuction with careful monitoring of respiratory vital capacity and aggressive ventilatory care for individuals that display respiratory failure. The only specific pharmacological treatment for botulism is administration of equine-derived botulinum antitoxin. On March 12, 2010, a new heptavalent botulinum antitoxin (HBAT, Cangene Corp.) became available through a US CDC-sponsored FDA Investigational New Drug (IND) protocol for the treatment of naturally acquired non-infant botulism (CDC, 2010). This antitoxin replaced the previously FDA-approved equine bivalent botulinum antitoxin $\mathrm{AB}$ and an investigational monovalent equine antitoxin E (BAT-AB and BAT-E, 
Sanofi Pasteur). HBAT contains equine-derived antibody against all BoNT serotypes: 7,500 U anti-A; 5,500 U anti-B; 5,000 U anti-C; 1,000 U anti-D; 8,500 U anti-E; 5,000 U anti$\mathrm{F}$; and 1,000 $\mathrm{U}$ anti-G per vial. This antitoxin is composed of $<2 \%$ intact immunoglobulin $\mathrm{G}$ (IgG) and $\geq 90 \% \mathrm{Fab}$ and $\mathrm{F}\left(\mathrm{ab}^{\prime}\right) 2$ immunoglobulin fragments created by despeciation (CDC, 2010). The recommended adult dosing is one $20 \mathrm{~mL}$ vial of HBAT (McLaughlin and Funk, 2010). BabyBIG®, human botulism immune globulin intravenous (BIG-IV), is an FDA-approved drug for the treatment of infant botulism types A and B. Available through the California Infant Botulism Treatment and Prevention Program, BabyBIG® is obtained from the pooled plasma of adults vaccinated with the pentavalent (A-E) botulinum toxoid who displayed high titers of neutralizing antibodies against BoNT/A and /B. Because BabyBIG® is of human origin, it does not carry the risk for anaphylaxis inherent with equine products, nor does BabyBIG® demonstrate a risk for possible lifelong hypersensitivity to equine antigens. BabyBIG® has been shown to significantly shorten the hospitalization period and reduce treatment costs up to $\$ 75,000.00$ per incident (Thompson et al., 2005; Fox, 2005).

Antitoxin can neutralize toxin molecules that are not yet bound to nerve endings and may limit the progression of the disease and prevent further nerve damage by clearing them from circulation. Thus, the antitoxin should be administered immediately upon a definitive diagnosis of botulism, preferably within $24 \mathrm{~h}$ after the onset of symptoms (Tacket et al., 1984; Chang and Ganguly, 2003). Compared to standard care alone, immediate administration of antitoxin has been shown to shorten time on respiratory support, and also reduced the hospitalization period (Shapiro et al., 1997; Tacket et al., 1984). It is not clear how long the toxin can persist in the bloodstream before clearance. Ravichandran reported that BoNT/A had a serum half-life of approximately 4 hours in small animal studies (Ravichandran et al., 2005). This study also suggested that blood does not sequester or modify the toxin in any detectable way. Thus, the blood may act as a reservoir for the toxin until it either enters the target cells or is eliminated from the body. Detectable levels of toxin were observed in one of the four patients in the Florida outbreak 8 days after receiving a massive overdose of an unlicensed preparation of BoNT/A during a cosmetic procedure (Chertow et al., 2006). Under such circumstances, antitoxin administration, even if delayed, may still be effective in limiting the duration of the illness. The use of equine-based antitoxins, but not the human product, has been associated with symptoms of hypersensitivity (including urticaria, serum sickness, and anaphylaxis). Hence, dermal testing is required before antitoxin administration. Due to the risk of adverse reactions, prophylactic antitoxin is not recommended in patients who are exposed to BoNT but have no symptoms. These patients may undergo gastric lavage or induced vomiting in an attempt to eliminate the toxin before absorption (Chan-Tack \& Bartlett, 2010).

\subsection{Prophylaxis}

In the United States, there is currently no FDA-licensed prophylactic product against botulism. Some of the earliest vaccine efforts were initiated during the second World War due to concerns that the toxin might be employed as an offensive biological weapon against the allied forces by Germany. A bivalent A/B toxoid vaccine was produced from 3-day culture autolysates of $C$. botulinum that were chemically neutralized with formaldehyde, filtered and adsorbed onto an alum adjuvant. While the vaccine did elicit the production of 
neutralizing antibodies, it also displayed a number of localized and systemic reactogenic effects (Reames et al., 1947). An improved product in which the A and B toxins were purified to $10-15 \%$ homomgeneity by acid-precipitation of the culture supernatants and adjuvanted onto aluminum phosphate was found to be well-tolerated in humans, displayed only minor localized reactogenic effects and produced significantly improved antibody titers over the previous bivalent toxoid (Fiock et al., 1961). A pentavalent ABCDE toxoid vaccine with $1 \%$ thymerosol as a preservative prepared by Parke, Davis and Company was administered to approximately 400 individuals (Fiock et al., 1963). The vaccine displayed minor reactogenic effects and elicted detectable antibody titers to all five serotypes. This product was administered to over 1600 individuals from 1970 to 1981 under an Investigational New Drug (IND) application. The Michigan Department of Public Health produced a pentavalent botulism (ABCDE) toxoid (PBT) using similar procedures as the Parke Davis product, but which contained roughly $50 \%$ of the formaldehyde and only $0.01 \%$ thymerosol, that has been administered under an IND to at-risk laboratory workers and military personnel. However, the declining immunogenicity, dwindling supplies and local reactogenic effects of the PBT (Rusnak \& Smith, 2009; CDC, 2009) have led to recent efforts to create new vaccines.

More contemporary toxoid vaccines have been created by chemical neutralization of the purified toxin (Keller, 2008; Jones, et al., 2008). However, large scale production of these products would require a secure, CDC-licensed facility to both propagate large amounts the bacterium and manipulate the purified toxin. Subsequent efforts have largely relied on the expression of recombinant protein antigens encoding one or more of the BoNT domains.

Codon optimized genes encoding the BoNT $(\mathrm{Hc})$ antigens produced in a $P$. pastoris expression platform have been successfully developed as a recombinant subunit vaccine against serotypes A-F and have been demonstrated to elicit protective immunity in both rodent (Smith, 2009; Rusnak \& Smith 2009) and non-human primates (Boles et al., 2006; Morefield, 2008). In February of 2011, the Dynport Vaccine Company announced that phase II clinical trials of a recombinant bivalent $\mathrm{Hc}$ vaccine against serotypes A and B (rBV A/B) had been completed and that full licensure would be sought. (CSC, 2011). Recombinant, catalytically inactive BoNT holoproteins made by mutagenesis of key amino acids residues have also been employed as potential vaccine candidates. A recombinant BoNT/C protein with active site mutations $\mathrm{H}^{229} \mathrm{G}, \mathrm{E}^{230} \mathrm{~T}$ and $\mathrm{H}^{223} \mathrm{~N}$ produced in $\mathrm{E}$. coli displayed no catalytic activity and elicited protective immunity against the parental toxin when delivered either subcutaneously or orally (Kiyatkin et al., 1997). Pier described the expression of a recombinant BoNT/A gene bearing $\mathrm{R}^{363} \mathrm{~A}$ and $\mathrm{Y}^{365} \mathrm{~F}$ mutations in the LNT01 nontoxigenic strain of C. botulinum (Pier et al., 2008). The recombinant protein was unable to cleave SNAP-25 and elicited protective immunity in mice when challenged with BoNT/A. Recombinant BoNT/A with active site mutations $\mathrm{H}^{223} \mathrm{~A}, \mathrm{E}^{224} \mathrm{~A}$ and $\mathrm{H}^{227} \mathrm{~A}$ produced in $P$. pastoris was found to be completely non-toxic and provided protective immunity in mice against $1000 \mathrm{MLD}_{50}$ of not only the parental toxin, but against subtypes / A2 and /A3 as well (Webb et al., 2009).

\subsection{Post-intoxication interventions}

Once the neurotoxic LC is endocytosed within the cytosol of peripheral cholinergic neurons, circulatory antibodies will no longer be effective at neutralizing the catalytic 
activity and ablating the toxicity. A number of recent research efforts have focused on the development of small-molecule inhibitors to reduce or eliminate the cleavage of SNARE proteins in neurons. The drawbacks associated with the use of peptides as drug candidates (e.g., poor tissue penetration, serum resistance, oral bioavailability, and quick elimination), and the potential usefulness of small molecules as pre- and post-exposure therapeutic agents have led many laboratories to instead pursue small-molecule approaches. To date, research has focused predominantly on developing small-molecule inhibitors that target the BoNT/A LC protease, due to the serotype's persistence and highly toxic nature. A number of BoNT/A small-molecule inhibitors, identified using conventional and novel approaches, have been reported that exhibit varying degrees of inhibitory capacity (Burnett et al., 2003; 2009; Boldt et al., 2006; Park et al., 2006; Tang et al., 2007; Capkova et al., 2007; 2009; Moe et al., 2009; Roxas-Duncan et al., 2009; Burnett et al., 2010). Most of these studies were conducted in vitro using truncated forms of the LC which might not be structurally representative of the intracellular form of BoNT. The inhibitors reported by Roxas-Duncan et al (2009), identified via a hierarchical screening strategy, were evaluated in vitro using both forms of LC (truncated and full-length), and ex vivo using mouse phrenic nerve hemidiaphragm preparations. Despite intensive efforts on small-molecule inhibitor discovery and development, no compound has been identified that would be suitable for preclinical testing. At present, there are only two reports of BoNT/A small-molecule inhibitors that have been tested in vivo. Janda and coworkers described a mouse toxicity bioassay in which two different inhibitors were injected intravenously immediately after an injection of 5-10 i.p. $\mathrm{LD}_{50}$ of BoNT/A. One compound, given at a $2.5 \mathrm{mM}$ dose, showed a $36 \%$ increase in time to death, while the other, given at a $1 \mathrm{mM}$ dose, resulted in a $16 \%$ overall survival rate (Eubanks et al., 2007). In another study, a single dose of three different inhibitors was administered i.p. at 2 $\mathrm{mg} / \mathrm{kg} 30 \mathrm{~min}$ prior to a challenge of $5 \mathrm{MLD}_{50}$ of BoNT/A (Pang et al., 2010). The control mice died within 12 hrs. All 3 inhibitors provided 100\% protection at 12 hrs and one compound provided $70 \%$ and $60 \%$ survival rates at 24 and 48 hrs; all three inhibitors provided a $10 \%$ overall survival rate with no signs of botulism at 5 days.

Recently, other regions of the LC, in addition to the BoNT active site, generated attention as potential targets for inhibition. Merrino et al., (2006) has focused on a family of bisimidazole BoNT/A inhibitors targeting the peripheral sites of substrate binding. Silhar et al., (2010) reported on D-chicoric acid, a natural product isolated from Echinacea, that inhibits BoNT/A LC by binding to an exosite.

\subsection{Human recombinant monoclonal antibodies}

Currently, immunotherapy is deemed as the most effective immediate response to BoNT exposure. However, BabyBig ${ }^{\circledR}$ is exclusively approved for use in infants, and equine antisera can induce serum sickness and anaphylaxis (Arnon et al., 2001; Arnon, 2004). Monoclonal antibody (mAb) combinations (oligoclonal antibodies) may be viable substitutes for polyclonal antisera (Nowakowski et al., 2002; Razai et al., 2005). Construction of scFv phage $\mathrm{Ab}$ libraries has enabled the generation of large panels of high-affinity binding monoclonal antibodies. Mouse neutralization studies revealed that effective protection is observed only when combinations of three or more mAbs are used (Nowakowski et al., 2002; Marks, 2004). Under the aegis of the National Institute of Allergy and Infectious 
Diseases (NIAID), antibody combinations that effectively protect against multiple BoNT/A, /B, and /E subtypes are currently being produced and tested to support FDA licensure. Antibodies that protect against the four remaining toxin serotypes (BoNT/C, /D, /F, and /G) are also in development.

\subsection{Antibodies specific for the catalytic light chain}

While a majority of the BoNT immunotherapy research has been focused on antibodies that bind the HC, efforts were also directed to explore the potential for antibodies that bind the enzymatic LC. Using a novel hybridoma method for cloning human antibodies (Adekar et al., 2008; Dessain et al., 2004), a fully human antibody specific for the BoNT/A LC was isolated which potently inhibited BoNT/A in vitro and in vivo, via mechanisms not previously associated with BoNT-neutralizing antibodies (Adekar et al., 2008). In another study, Dong et al. (2010) created a library of non-immune llama single-domain VHH (camelid heavy-chain variable regions) displayed on the surface of the yeast Saccharomyces cerevisiae. Library selections against BoNT/A LC yielded 15 yeast-displayed VHHs, eight of which inhibited the cleavage of substrate SNAP-25 by BoNT/A LC. The most potent VHH (Aa1) had a solution $\mathrm{K}(\mathrm{d})$ of $1.47 \times 10^{-10} \mathrm{M}$ and an $\mathrm{IC}_{50}$ of $4.7 \times 10^{-10} \mathrm{M}$. X-ray crystal structure of the BoNT/A LC-Aa1 VHH complex revealed that the Aa1 VHH binds the alpha-exosite region of BoNT/A LC. Recently, Tremblay et al. (2010) reported on the selection of small (14 $\mathrm{kDa}$ ) binding domains specific for the protease of BoNT serotypes A or B from libraries of VHHs or nanobodies cloned from vaccinated alpacas. Several VHHs were demonstrated to exhibit high affinity $\left(K_{\mathrm{D}}\right.$ near $\left.1 \mathrm{~nm}\right)$ and were potent inhibitors of BoNT/A LC (Ki near 1 $\mathrm{nM}$ ); a VHH inhibitor of BoNT/A LC was able to protect BoNT/A-mediated SNAP25 cleavage.

\subsection{Inhibitors of internalization and translocation}

Several compounds that inhibit the acidification process of endosomes by various mechanisms have been evaluated for both toxicity and ability to inhibit BoNT-induced synaptic failure. Lysosomotropic agents ammonium chloride and methylamine hydrochloride have been shown to antagonize the toxin internalization step by delaying the time-to-block of nerve-evoked muscle contractions after exposure to BoNT/A, /B, /C1, and TeNT (Simpson, 1983). However, these amines act by inhibiting the acidification process of endosomes; they do not selectively inactivate the toxins nor irreversibly modify tissue function at concentrations that inhibit the onset of BoNT-induced paralysis. Other candidates that have been examined were uncouplers of oxidative phosphorylation $\mathrm{CCCP}$, FCCP (Adler et al., 1994), and vesicle $\mathrm{H}^{+}$-ATPase inhibitors including Bafilomycin A, which was shown to antagonize BoNTs A-G (Simpson et al., 1994). Some of these compounds were toxic or had low safety margins, hence they were deemed unsuitable as therapeutic candidates.

Anti-malarial compounds chloroquine and hydroxychloroquine have also been evaluated for potentially inhibiting BoNT-mediated internalization (Simpson, 1982). The efficacy of these agents was found similar to that of ammonium chloride and methylamine hydrochloride; both groups also exhibited a comparable therapeutic window. Deshpande and co-workers (1997) extended the studies on antimalarial agents by examining a large 
group of 4- and 8-aminoquinolines. Unfortunately, these compounds failed to extend the therapeutic window. The most effective compounds were 4 -aminoquinolines and quinacrine that delayed BoNT/A-induced neuromuscular block by more than threefold compared to the control (toxin only) values. Maximum protection was solely achieved when the tissues were exposed to the compounds before or at the same time as the toxin treatment; a delay of $>20$ min abolished the inhibitory capacity of these compounds.

An additional approach to prevent or reduce BoNT internalization has been attempted by treating nerve-muscle preparations with the protein ionophores nigericin and monensin (Adler et al., 1994; Sheridan, 1996). These ionophores block vesicle acidification by acting as $\mathrm{H}^{+}$shunts to neutralize $\mathrm{pH}$ gradients, thereby interfering with the delivery of active LC in the cytosol. Though the efficacy of these ionophores was observed to be comparable to other inhibitors of internalization, they were more toxic; high concentrations resulted in a depression of neuromuscular transmission (Adler et al., 1994; Sheridan, 1996).

\subsection{Compounds that restore neuronal function}

A known potassium channel blocker, 3,4-diaminopyridine (3,4-DAP) was evaluated for its ability to antagonize BoNT-induced depression of tension in rat diaphragm muscles (Adler et al., 1995). BoNT-induced paralysis was nearly completely inhibited after addition of 100 $\mathrm{uM}$ of 3,4-DAP, and this effect was sustained even after $4 \mathrm{~h}$ of treatment. The antagonistic effects of 3,4-DAP was also demonstrated in vivo, provided its concentration in the plasma is maintained at $\sim 30 \mu \mathrm{M}$ during the course of intoxication (Adler et al., 2000). However, 3,4DAP is generally toxic, thus, its high drug concentration requirement prohibits routine therapeutic use (Millard, 2006).

Mastoparan, a phospholipase activator, was evaluated for its ability to attenuate BoNT intoxication. Addition of mastoparan and $80 \mathrm{mM} \mathrm{K}+$ completely prevented BoNT inhibition of radiolabeled acetylcholine in PC12 cells, but this effect was blocked by either EGTA or the $\mathrm{N}$-type calcium channel blocker $\omega$-conotoxin (Ray et al., 1999). These findings imply that the effects of mastoparan are dependent on $\mathrm{Ca}^{2+}$ influx via the neuronal type voltage-sensitive $\mathrm{Ca}^{2+}$ channels.

\subsection{Drug delivery vehicle research}

One significant challenge in the development of BoNT small-molecule therapeutics is the delivery of the compounds to the cytosol of peripheral cholinergic nerve cells (PCNC), which are the sites of BoNT action. In combination with the discovery and development of BoNT small-molecule inhibitors, cell-specific intracellular targeting is critical to increase the therapeutic index and minimize potential systemic toxicity associated with the drug treatment. Several studies have examined the potential of using specific recombinant BoNT domains or a neutralized full-length BoNT holoprotein as drug delivery system. Goodnough et al. observed that BoNT/A and unlabeled rHC were able to compete for binding, implicating specific neuronal targeting (Goodnough et al., 2002). The efficiency of neuron-specific cargo delivery into the cytosol was evaluated by coupling labeled dextran to a recombinant BoNT/A HC using a 3-(2-pyridylthio)-propionyl hydrazide linker (Zhang et al., 2009). A florescent tracking dye was conjugated to the dextran moiety and incubated in mouse cultured mouse spinal cord neurons. The binding of the fluorescent tag and its 
internalization into the endosomes were observed, but minimal levels were detected in the cytosol. The movement of a small, membrane-permeable dye from the endosome into the cytosol is hypothesized to be due to passive diffusion instead of an active translocation event. Ho et al (2010) reported on a recombinant BoNT/A HC with an amino terminal GFP fusion that was internalized into mouse neurons; however, the GFP cargo was observed to be almost exclusively limited to endocytotic vesicles, with little detectable translocation into the cytosol.

Although the of BoNT heavy chain comprises the domains necessary for binding and internalization into endosomes, recent studies suggest that all or part of the LC is essential to translocate a ligated cargo into the cytosol.

Recombinant BoNT/D fusion proteins bearing amino terminal GFP, luciferase, dihydrofolate reductase or BoNT/A LC protein were found to promote translocation of cargo proteins into the cytosol in an enzymatically active form (Bade et al., 2004). A recombinant neutralized BoNT/A bearing an $\mathrm{E}^{224} \mathrm{~A} \mathrm{E}^{262} \mathrm{~A}$ double mutation, labeled with Alexa-488, has been shown to specifically bind and internalize into human SH-SY5Y neuroblastoma cells (Sing et al., 2010). Additionally, this protein was found to marginally bind to the surface of human rhabdomyosarcoma cells with a toxicity limit of $1 \mu \mathrm{g}$ in mice. No additional information is available regarding the drug conjugation study on this protein. Moreover, recombinant versions of full-length BoNT/A holotoxin devoid of catalytic activity were recently developed (Pier et al., 2008; Webb et al., 2009; Yang et al., 2008) which could be potentially used to deliver conjugated therapeutic cargoes.

\section{Emergency preparedness and public response}

The 2007 anthrax attacks in the United States illustrated the need to develop a comprehensive preparedness plan for identifying and managing healthcare resources in the event of a biological attack. Anthrax, plague, botulinum toxins, smallpox, tularemia, and viral hemorrhagic fever viruses have been identified as having a significant potential for use in a bioterrorism attack because they can be easily disseminated or transmitted, have high morbidity or mortality rates and would cause widespread social disruption (Rotz et al., 2002). A bioterrorism attack involving dissemination of BoNT by existing food or water distribution networks is theoretically possible but this route is associated with significant logistical difficulties (Franz, et al., 1997; Zilinskas, 1999) and most experts believe that an aerosol dispersion poses the greatest threat (Arnon, 2002). Because botulism is a relatively rare disease, clinicians and the healthcare infrastructure in general have limited experience in diagnosis of any form of the disease. A 2005 study reported that of 631 physicians participating in a mock bioterrosim event, slightly less than half provided an accurate diagnosis and plan of management for botulism (Cosgrove, 2005). In the event of a biological attack with BoNT, a rapid and accurate diagnosis of the agent by physicians and clinical laboratories would be crucial to an equally rapid response and mobilization of equipment and biological agents for management. Health care providers who suspect botulism should immediately call their state health department's emergency 24-hour emergency telephone number. The state health department will contact the CDC to report suspected botulism cases, arrange for a clinical consultation by telephone and, if indicated, request release of botulinum antitoxin. State health departments should call the CDC 24hour telephone number at 770-488-7100. The call will be taken by the CDC Emergency 
Operations Center, which will page the Foodborne and Diarrheal Diseases Branch medical officer on call. The CDC established the Laboratory Response Network (LRN) in 1999; a national network of about 150 federal, state, local and military labs that can respond to biological and chemical terrorism, and other public health emergencies (CDC-EPR). The LRN hierarchy also includes reference labs that can perform tests to detect and confirm the presence of a threat agent to ensure a rapid local response in the event of a bioterrorism incident without having to rely on confirmation from CDC labs. Sentinel labs are comprised of thousands of hospital-based labs that have direct contact with patients. These labs might well be the first facility to spot a suspicious specimen and refer it to the appropriate reference lab (Sentinel, ASM).

The ability of the government and healthcare infrastructure to respond to a bioterroism attack using BoNT in a densely populated urban environment would largely dictated be by the ventilator and antitoxin supplies and how quickly they could be mobilized to the outbreak area. Approximately 120,000 of the 200,000 doses of the HBAT contracted by the Biomedical Advanced Research and Development Authority (BARDA) have been delivered for use in the US national strategic stockpile and the remaining 80,000 doses are scheduled for delivery by 2014. A 2010 study estimated that there are approximately 63,066 fullfeatured mechanical ventilators in the US, $46.4 \%$ of which were capable of ventilating pediatric and neonatal patients (Rubinson et al, 2010). Additionally, there was an estimated 82,775 additional positive pressure ventilators (PPV) that could be brought on-line in response to an acute respiratory failure (ARF) surge event. This study may represent a conservative estimate as it only accounted for survey responders and it did not consider the various units rented by hospitals, those facilities who failed to respond to the survey or those at nursing facilities or schools.

\section{Conclusion}

BoNT has been investigated as a BW by a number of different state-sponsored initiatives and terrorist organizations and is considered a biological threat to both our military and the public. Effective medical countermeasures against BoNT intoxication are limited. Currently, the only available treatment other than supportive care is a new investigational botulinum heptavalent equine-based antitoxin. However, antitoxin cannot intervene in the pathogenesis of the disease once the toxin enters the nerve cell, and cannot support all those infected in the event of a biological terrorist attack. Hence, there is a critical need for postintoxication therapy that can be administered rapidly and effectively to a large infected population. Because small molecules provide an opportunity to treat botulism both before and after cellular intoxication has occurred, considerable research efforts have been devoted to the development of these types of inhibitors. A number of strong contributions to the field have been made, yet no small molecule inhibitor was identified that possesses the appropriate characteristics (safety, efficacy, solubility) required to be a pharmaceutical intervention.

Research studies addressing these obstacles are underway. Continuing efforts will be facilitated particularly by the availability of structural information and by knowledge of the mechanism of the BoNT LC-mediated proteolysis of SNARE proteins. Additionally, potential novel strategies to therapeutic development, e.g., host-directed therapeutics, and 
targeting pathways involved in the cellular response to BoNT intoxication, are being explored. An understanding of these mechanisms may provide insight into the design and development of innovative and effective therapeutic strategies to counteract BoNT intoxications.

\section{References}

Adekar S.P., Jones, R.M. \& Elias, M.D., et al. (2008). Hybridoma populations enriched for affinity-matured human IgGs yield high-affinity antibodies specific for botulinum neurotoxins. J Immunol Methods, Vol.333, No.1-2, pp. 156-166, ISSN 0022-1759

Adler, M., Deshpande, S.S. \& Sheridan, R.E., (1994). Evaluation of captopril and other potentially therapeutic compounds in antagonizing botulinum toxin-induced muscle paralysis, In: Therapy with Botulinum Toxin; Jankovic, J., \& Hallett, M. (Eds). pp. 6370, Marcel Dekker Inc., ISBN 0824788249, New York, NY, USA

Adler, M., Scovill, J. \& Parker, G., et al. (1995). Antagonism of botulinum toxin-induced muscle weakness by 3,4-diaminopyridine in rat phrenic nerve-hemidiaphragm preparations. Toxicon, Vol.33, No.4, pp. 527-537, ISSN 0041-0101

Adler, M., Capacio, B. \& Deshpande, S.S. (2000) Antagonism of botulinum toxin A-mediated muscle paralysis by 3, 4-diaminopyridine delivered via osmotic minipumps. Toxicon, Vol.38, No.10, pp. 1381-1388, ISSN 0041-0101

Alberts, B. (2005). Modeling attacks on the food supply. PNAS, Vol.102, No.8, pp. 9737-9738, ISSN 0027-8424

Alibek, K. \& Handleman, S. (1999). Biohazard. Dell Publishing, ISBN, 0385334966, New York, New NY.

Arezzo, J.C., Litwak, M.S. \& Caputao, F.A., et al. (2000). Spread of paralytic activity of Neurobloc $^{\mathrm{TM}}$ (botulinum toxin type B) and Botox ${ }^{\circledR}$ (botulinum toxin type A) in juvenile monkeys: an electrophysiological model. Eur J Neurol, Vol.8, No.S4, pp. 26 ISSN 1351-5101

Arnon, S. (1998) Infant botulism, In: Textbook of pediatric infectious diseases, Feigen, R. And Cherry, J. (Ed), 4th ed. W. B. Saunders, pp. 1570-1577, ISBN 0721664482 Philadelphia, PA, USA.

Arnon, S. (1999) Botulism as an intestinal toxaemia, In: Infections of the gastrointestinal tract, M.J. Baser, Guerrant, R.L. \& P.D. Smith, et al. (Ed.), pp. 257-271, Raven Press, ISBN: 0781702267, New York, NY, USA.

Arnon, S.S., Schechter, R. \& Inglesby, T., et al. (2001). Botulinum toxin as a biological weapon. Medical and public health management. JAMA, Vol.285, No.1, pp. 10591070, ISSN 0098-7484

Arnon SS. (2004). Infant Botulism. In: Textbook of Pediatric Infectious Diseases, Feigin, R.D., Cherry, J., \& Demmler, G.J. (Eds) pp. 1758-1766, Saunders, ISBN 0721693296. Philadelphia, PA, USA

Bade, S., Rummel, A. \& Reisinger, C., et al. (2004). Botulinum neurotoxin type D enables cytosolic delivery of enzymatically active cargo proteins to neurons via unfolded translocation intermediates. J Neurochem, Vol.91, No.6, pp. 1461-1472, ISSN 00223042 
Bakheit, A.M., Ward, C.D. \& McClellan D.L. (1997) Generalised botulism-like syndrome after intramuscular injections of botulinum toxin type A: a report of two cases. $J$ Neurology, Neurosurgery and Psychiatry, Vol.62, No.2, pp. 198, ISN 0022-3050

Baird-Parker, A.C. \& Freame, B. (1967). Combined effect of water activity, pH and temperature on the growth of Clostridium botulinum from spore and vegetative cell inocula. J Appl Bact, Vol.30, No.2, pp. 420-429, ISSN 0021-8847

Barash, J.R., Tang, T.W.H., \& Arnon S.S. (2005). First case of infant botulism caused by Clostridium baratii type F in California. J Clin Microbiol, Vol.43, No.8, pp. 4280-4282, ISSN 0095-1137

BB-IND 61 Protocol CDC IBR\#392, version 8.0. IND protocol: Use of penatavalent (ABCDE) botulinum toxin aluminum phosphate adsorbed (PBT) for workers at risk of occupational exposure to botulinum neurotoxins. Spnsored by: Centers for Disease Control and Prevention, Atlanta, GA. October 6, 2009.

Bleck, T.P. (2009). Botulism as a potential agent of bioterrorism, In: Bioterrorism and Infectious Agents: A New Dilemma for the 21st Century, Fong, I.W. \& Alibek, K. (Eds), pp.193202, Springer, ISBN 1441912657, Ney York, NY, USA

Blix, H. (2004) Disarming Iraq. (1st ed.), Pantheon, ISBN 0375423028, New York, NY, USA.

Benson, S.B., Passaro, D. \& McGee, J., et al. (2000) Wound botulism in California, 1951-1998: Recent epidemic in heroin injectors. Clin Infec Dis, Vol.31, No.4, pp.1018-1024, ISN 1058-4838

Boles, J., West, M. \& Montgomery, V.A., et al. (2006). Recombinant C fragment from botulinum neurotoxin B serotype $(\mathrm{rBoNTB}(\mathrm{Hc}))$ immune responses and protection in the rhesus monkey. Toxicon, Vol.47, No.9 pp.877-884, ISSN 0041-0101

Boldt, G.E., Eubanks L.M. \& Janda K.D. (2006). Identification of a botulinum neurotoxin A protease inhibitor displaying efficacy in a cellular model. Chem Commun (Cambridge) Vol.29, pp.3063-3065, ISSN 1359-7345

Bozheyeva, G., Kunakbayev, Y. \& Yeleukenov, D. (1999). Former soviet biological weapons facilities in Kazakhstan: past, present and future. Occasional paper No.1. Monterey, CA. Center for Nonproliferation Studies, Monterey Institute for International Studies, pp. 1-20

Burnett, J.C., Schmidt, J. \& Stafford, R.G., et al. (2003). Novel small-molecule inhibitors of botulinum neurotoxin A metalloprotease activity. Biochem Biophys Res Commun, Vol.310, No.1, pp. 84-93, ISSN 0006-291X

Burnett, J.C., Wang. C., \& Nuss, J.E., et al. (2009). Pharmacophore-guided lead optimization: the rational design of a non-zinc coordinating, submicromolar inhibitor of the botulinum neurotoxin serotype A metalloprotease. Bioorg Med Chem Lett, Vol.19, No.19, pp. 5811-5813, ISSN 0960-894X

Burnett, J.C., Li, B. \& Pai, R., et al. (2010). Analysis of botulinum neurotoxin serotype A metalloprotease inhibitors: analogs of a chemotype for therapeutic development in the context of a three-zone pharmacophore. Open Access Bioinformatics 2: 11-18. DOI 10.2147/OAB.S7251

Burrows, W.D., Valcik, J.A. \& Seitzinger, A. (1997). Natural and terrorst threats to drinking water supplies. In, Proceedsing of the 23rd environmental symposium, 7-10 April 1997, New Orleans, LA, American Defense Preparedness Association 
Carrus, S. (2001) Bioterroism and biocrimes. The illicit use of biological agents since 1900. Center for counterproliferation research, National Defense University, pp.90, ISBN 1410100235, Washington, D.C., USA

CDC. (1998). Botulism in the United States, 1899-1996. Handbook for epidemiologists, clinicians, and laboratory workers. Atlanta, GA: Centers for Disease Control and Prevention. Available at http://www.cdc.gov/ncidod/dbmd/diseaseinfo/files/botulism.PDF

CDC. Emergency preparedness and response (EPR). Facts about the laboratory response network. Accessed 08/01/2011, http://www.bt.cdc.gov/lrn/factsheet.asp

CDC. (2010). Investigational heptavalent botulinum antitoxin (HBAT) to replace licensed botulinum antitoxin AB and investigational botulinum antitoxin E. MMWR 59: 229.

CDC. National Botulism Surveillance (NBS), accessed 08-23-2011, available from http://www.cdc.gov/nationalsurveillance/botulism_surveillance.html

CDC (2006). Botulism associated with commercial carrot juice - Georgia and Florida, September 2006. MMWR weekly, October 13, 2006/55(40), pp. 1098-1099.

CDC. (2007). Botulism Associated with Commercial Carrot Juice --- Georgia and Florida, September 2006, 08/24/2011, Available from:

http://www.cdc.gov/mmwr/preview/mmwrhtml/mm5540a5.htm

CDC. (2008). Public Health Preparedness: Mobilizing State by State http:/ / www.bt.cdc.gov/publications/feb08phprep/

Capková, K., Yoneda, Y. \& Dickerson, T., et al. (2007). Synthesis and structure-activity relationships of second-generation hydroxamate botulinum neurotoxin A protease inhibitors. Bioorg Med Chem Lett, Vol.17, No.23, pp. 6463-6466, ISSN 0960-894X

Capková, K., Hixon, M.S. \& Pellett, S. et al. (2009). Benzylidene cyclopentenediones: First irreversible inhibitors against botulinum neurotoxin A's zinc endopeptidase. Bioorg Med Chem Lett, Vol.20, No.1, pp. 206-208, ISSN 0960-894X

Chang, G.Y., \& Ganguly, G. (2003). Early antitoxin treatment in wound botulism results in better outcome. Eur Neurol, Vol.49, No.3, pp. 151-153, ISSN 0014-3022

Chan-tack, K.M., \& Bartlett J. (2010). Botulism. http:/ / emedicine.medscape.com/article/213311-overview

Chia, J., Clark, J. \& Ryan, C. (1986). Botulism in an adult associated with food-borne intestinal infection with Clostridium botulinum. NEJM, Vol.6, No.4, pp. 239-241, ISSN 0028-4793

Chen, R., Karp, B.I. \& Hallett, M. (1998). Botulinum toxin type F for treatment of dystonia: Long-term experience. Neurology, Vol.51, No.5, pp. 1494-1496, ISSN 0028-3878

Chertow, S., Tan, E.T. \& Maslanka, S.E. et al. (2006). Botulism in 4 adults following cosmetic injections with an unlicensed, highly concentrated botulinum preparation. JAMA, Vol.296, No.20, pp.2476-2479, ISSN 0098-7484

Cochrane, R.C. (1947). Biological warfare research in the United States, In: History of chemical warfare service in world war II (01 July 1940-15 August 1945). Vol.2, historical sections, plans, training and intelligence division, office of the chief chemical corps, US department of the army, 1947. Unclassified. Archived at the US Army Medical Research Institute for Infectious Diseases, Fort Detrick, MD.

Collins, M.D. \& East A.K. (1998). Phylogeny and taxonomy of the food-borne pathogen Clostridium botulinum and its neurotoxins. J App Micro, Vol.84, No.1, pp. 5-17, ISSN 1364-5072 
Cornblath, D.R., Sladky, J.T. \& Sumner, A.J. (1998). Clinical electrophysiology of infantile botulism. Muscle Nerve, Vol.6, No.6, pp. 448-452, ISSN 0148-639X

Cosgrove, S.E., Perl, T.M. \& Song, X., et al. (2005) Ability of physicians to diagnose and manage illness due to category A bioagents. Arch Int Med, Vol.165, No.17, pp. 20022006, ISSN 0003-9926

CSC Press Release. (2011). CSCs DynPort Vaccine Company Completes Vaccinations and Study Visits in Phase 2 Botulinum Vaccine Clinical Trial, Febraury 11, 2011, http://www.csc.com/dvc/press_releases/60409-

cscs_dynport_vaccine_company_completes_vaccinations_and_study_visits_in_pha se_2_botulinum_vaccine_clinical_trial, accessed 08/01/2011

Davis, J.B., Mattman, L.H. \& Wiley, M. (1951). Clostridium botulinum in fatal wound infection. JAMA, Vol.146, No.7, pp. 646-648, ISSN 0098-7484

DasGupta, B. (1989). The structure of botulinum neurotoxins, In: Botulinum Neurotoxin and Tetanus Toxin, pp. 53-67, Academic Press, Inc., ISBN 0306444127, New York, NY, USA

Dembek, Z.F., Smith, L.A. \& Rusnak, J.M. (2007). Botulinum toxin: Cause, effects, diagnosis, clinical and laboratory identification, and treatment modalities. Dis Med Pub Health Prep, Vol.1, No.2, pp. 122-134, ISSN 1935-7893

Deshpande, S.S., Sheridan, R.E. \& Adler, M. (1995). A study of zinc-dependent metalloendopeptidase inhibitors as pharmacological antagonists in botulinum neurotoxin poisoning. Toxicon, Vol.33, No.4, pp. 551-557, ISSN 0041-0101

Deshpande, S.S., Sheridan, R.E. \& Adler, M. (1997). Efficacy of certain quinolines as pharmacological antagonists in botulinum neurotoxin poisoning. Toxicon, Vol.35, No.3, pp. 433-435, ISSN 0041-0101

Dessain, S.K., Adekar, S.P. \& Stevens, J.B., et al. (2004). High efficiency creation of human monoclonal antibody-producing hybridomas. J Immunol Methods, Vol.291, No.1-2, pp. 109-122, ISSN 0022-1759

Dong, M., Yeh, F. \& Tepp, W. H., et al. (2006). SV2 Is the Protein Receptor for Botulinum Neurotoxin A. Science, Vol.312, No.5773, pp. 592-596, ISSN 0036-8075

Dunbar, E.M. (1990). Botulism, J Infect, Vol.20, No.1, pp. 1-3, ISSN 0163-4453

Eleopra, R., Tugnoli, V. \& Rosetto, O., et al. (1997). Botulinum neurotoxin serotype C: a novel effective botulinum therapy in humans. Neurosci Letters, Vol.224, No.2, pp.9194, ISSN 0304-3940

Eleopra, R., Tugnoli, V. \& Rosetto, O., et al. (1998a). Different time courses of recovery after poisoning with botulinum neurotoxin serotypes $\mathrm{A}$ and $\mathrm{E}$ in humans. Neurosci Letters, Vol.256, No.3, ISSN 0304-3940, pp. 135-138

Eleopra, R., Tugnoli, V. \& De Grandis, D., et al. (1998b). Botulinum toxin serotype C treatment in subjects affected by focal dystonia and resistant to toxin serotype A. Neurology, Vol.50, No.S4, pp. A72, ISSN 0028-3878

Eleopra, R., Tugnoli, V, \& Rocco, Q., et al. (2004). Different types of botulinum toxins in humans. Movement Disorders, Vol.19, No.S8, pp. S53-S59, ISSN 0885-3185

Eubanks, L. M., Hixson, M. S., W. \& Jin, W., (2007). An in vitro and in vivo disconnect uncovered through high-throughput identification of botulinum neurotoxin A antagonists. PNAS, Vol.104, No.8, pp. 2602-2607, ISSN 0027-8424 
Feneica, L., Franciosa, G. \& Pourshaban, M. (1999). Intestinal toxemia botulism in two young people, caused by Clostridium botulinum type E. Clin Inf Dis, Vol.29, No.6, pp. 13811387, ISSN 1058-4838

Fiock, M.A., Device, L.F. \& Gearinger, et al. (1962). Studies on immunity to toxins of Clostridium botulinum VIII. Immunological reponses of man to purified bivalent botulinum toxoid. J Immun, Vol.88, No.3, ISSN 0022-1767

Fiock, M.A., Cardell, A. \& Gearinger, N.F. (1963) Studies on immunity to toxins of Clostridium botulinum IX. Immunological response of man to purified pentavlent ABCDE botulinum toxoid. J Immunology, Vol.90, No. 5, pp.697-702, ISNN 0022-1767

Fox, C.K., Keet, C.A., \& Strober, J.B. (2005). Recent advances in pediatric botulism. Pediatr Neurol, Vol.32, No.3, pp. 149-154, ISSN 0887-8994

Franz, D., Parrott, C. \& Takafuji, E. (1997). The U.S. Biological Warfare and Biological Defense Programs. In: Textbook of Military Medicine, Part I: Warfare, Weaponry, and Then Casualty: Medical Aspects of Chemical and Biological Warfare, Slidell, F., Takafuji, E. \& Franz, D (Eds.) Borden Institute, Walter Reed Washington, DC, USA.

Franz, D.R., Jahrling, P.B. \& Friedlander, A.M., et al. (1997). Clinical recognition and management of patients exposed to biological warfare agents. JAMA, Vol.278, No.5, pp. 399-411, ISSN 0098-7484

Freedman, M., Armstrong, R.M. \& Killian, J.M. (1986) Botulism in a patient with jejunoileal bypass. Ann Neurol, Vol.20, No.5, pp. 641-643, ISSN 0364-5134,

Gupta, A., Sumner, C.J. \& Castor M, et al. (2005). Adult botulism type F in the United States, 1981-2002. Neurology, Vol.65, No.11, pp. 1694-700, ISSN 0028-3878

Goodnough, M.C., Oyler, G. \& Fishman, P.S., et al. (2002). Development of a delivery vehicle for intracellular transport of botulinum neurotoxin antagonists. FEBS Lett, Vol.513, No.2-3, pp. 163-168, ISSN 0014-5793

Hatheway, C.L. (1988). Botulism, In: Laboratory Diagnosis of Infectious Diseases Principles and Practice, Balows A., Hausler, J.W.J. \& Ohashi, M. et al. (Eds), pp. 111-133, ISBN 0387967559, Springer Scientific, New York, NY, USA

Hatheway C.L. (1993). Clostridium botulinum and other clostridia that produce botulinum neurotoxin, In: Clostridium botulinum: Ecology and control in foods. Hauschild A.H.W. \& Dodds K.L. (Eds), pp. 3-20, Marcel Dekker, Inc., ISBN 082478748X, New York, NY, USA.

Hill K.K., Smith T.J. \& Helma C.H., et al. (2007). Genetic diversity among botulinum neurotoxin-producing clostridial strains. J Bact, Vol.189, No.3, pp 818-832, ISSN 0021-9193

Ho, M., Chang, L.H., \& Pires-Alves, M., et al. (2010). Recombinant botulinum neurotoxin A heavy chain-based delivery vehicles for neuronal cell targeting. Prot Eng Des Sel, Vol.24, No.3, pp 247-253, ISSN 1741-0126

Holzer, E. (1962) Botulism caused by inhalation. Medizinische Klinik, Vol.31, pp.1735-740, ISSN 0723-5003

Hörman, A., Nevas, M., \& Lindström, M., et al. (2005). Elimination of botulinum neurotoxin (BoNT) type B from drinking water by small-scale (personal use) water purification devices and detection of BoNT in water samples. App Env Micro, Vol.71, No.4, pp. 1941-1945, ISSN 1098-5336 
Hughes, J.M., Blumenthal, J.R. \& Merson, M.D., et al. (1981) Clinical features of types A and B food-borne botulism. Ann Int Med, Vol.95, No.4, pp. 442-445, ISSN 0003-4819

Jones, R.G.A, Liu, Y. \& Rigsby, P. (2008). An improved method for development of toxoid vaccines and antitoxins. J Immun Meth, Vol.137, No.1, pp. 42-48, ISSN 0022-1759

Keller, J.E. (2008). Characterization of new formalin-detoxified botulinum neurotoxin toxoids. Clin Vacc Imm, Vol.15, No.9, pp.1374-1379, ISSN 1556-6811

Kyatkin, N., Maksymowych, \& Simpson, L.A. (1997). Induction of an immune response by oral administration of recombinant botulinum toxin. Inf Imm, Vol.65, No.11, pp. 4586-4591, ISSN 0019-9567

Leitenberg, M. (1999). Aum Shinrikyo's efforts to produce biological weapons: A case study in the serial propagation of misinformation. Terrorism and Political Violence, Vol.11, No.4, pp. 152-158, ISSN 0954-6553

Long, S.S., Gajewski, J.L. \& Brown, L.W., et al. (1985). Clinical, laboratory and environmental features of environmental botulism in southeastern Pennsylvania. Pediatrics, Vol.75, No.5, pp. 935-941, ISSN 0031-4005

Marks, J.D. (2004). Deciphering antibody properties that lead to potent botulinum neurotoxin neutralization. Mov Disord, Vol.19, No.S8, pp. S101-108, 0885-3185

Mezaki, T., Kaji, R. \& Kohara, N., et al. (1995). Comparison of Therapeutic Efficacies of Type A and F Botulinum Toxins for Blepharospasm: A double-blind, controlled study. Neurology, Vol.45, No.3, pp. 506-508, ISSN 0028-3878

Merino, I., Thompson, J.D. \& Millard CB, et al. (2006). Bis-imidazoles as molecular probes for peripheral sites of the zinc endopeptidase of botulinum neurotoxin serotype A. Bioorg Med Chem, Vol.14, No.10, pp. 3583-3591, ISSN 0968-0896

Middlebrook, J.L., \& Franz, D.R. (1997). Botulinum toxins. In: Textbook of Military Medicine, Part I: Warfare, Weaponry, and Then Casualty: Medical Aspects of Chemical and Biological Warfare, Sidell, F.R., Takafuji, E.T., \& Franz, D.R., (Eds.) pp. 643-54. Borden Institute, Walter Reed Army Medical, Center Washington, DC, USA.

Millard, C. (2006). Medical defense against toxin weapons: review and perspective. In: Infectious disease: biological weapons defense: infectious diseases and counterterrorism, Lindler, L.E., Lebeda F.J. \& Korch G.W. (Eds.), pp. 255-276, Humana Press, Inc., ISBN 1588291847, Totowa, NJ, USA

McLaughlin J, Funk B. 2010. New recommendations for use of heptavalent botulinum antitoxin (HBAT). State of AK Bull 5:1. http://www.epi.Alaska.gov

Moe, S.T., Thompson, A.B., \& Smith, G.M. et al. (2009). Botulinum neurotoxin serotype A inhibitors: Small-molecule mercaptoacetamide analogs. Bioorgan Med Chem, Vol.17, No.8, pp. 3072-3079, ISSN 0968-0896

Moorefield, G.L., Tamariello, R., \& Purcell, B. et al. (2008). An alternative approach to combination vaccines: intradermal administration of isolated components for control of anthrax, botulism, plague and staphylococcal toxic shock. J Immune Based Ther Vacc, Vol.6, No.5, pp. 1-11, ISSN 1476-8518

Nowakowski, A., Wang, C. \& Powers, D.B. et al. (2002). Potent neutralization of botulinum neurotoxin by recombinant oligoclonal antibody. PNAS, Vol.99, No.17, pp. 1134611350, ISSN 0027-8424 
Notermans, S. \& Havelaar, A.H. (1980). Removal and inactivation of botulinum toxins during production of drinking water from surface water. Antonie van Leeuwenhoek, Vol.46, No.5, pp. 511-514, ISSN 0003-6072

Pang, Y.P., Davis, J., \& Wang, S., et al. (2010). Small molecules showing significant protection of mice against botulinum neurotoxin serotype A. PLoS ONE, Vol. 5, No. 4, pp. e10129, ISSN 1932-6203

Park, J.G., Sill, P.C. \& Makiyi, E.F. et al. (2006). Serotype-selective, small-molecule inhibitors of the zinc endopeptidase of botulinum neurotoxin serotype A. Bioorg Med Chem, Vol.14, No.2, pp. 395-408, ISSN 0968-0896

Parker, H.S. (2002) Agricultural Bioterrorism: A federal strategy to meet the threat. McNair paper 65, Institute for National Strategic Studies, ISSN 1071-7552, Washington D.C., USA

Partikan, A., \& Mitchell, W.G. (2007). Iatrogenic botulism in a child with spastic quadriparesis. J Child Neur, Vol.16, No.22, pp. 1235-1237, 0883-0738

Pickett, J., Berg, B. \& Chaplin, E. et al. (1976). Syndrome of botulism in infancy: clinical and electrophysiological study. NEJM, Vol.295, No.14, pp.770-772, ISSN 0028-4793

Pier, C.L., Tepp, W.H., \& Bradshaw, M., et al. (2008). Recombinant holotoxoid vaccine against botulism. Infect Immun, Vol.76, No.1, pp. 437-42, ISSN 0019-9567

Ravichandran, E., Gong, Y. \& Fetwah, H. et al. (2005). An initial assessment of the systemic pharmacokinetics of botulinum toxin. J Pharm Exp Ther, Vol.318, No.3, pp. 13431351, ISSN 0022-3565

Ray, P., Ishida, H. \& Millard, C.B., et al. (1999). Phospholipase A2 and arachidonic acidmediated mechanism of neuroexocytosis: a possible target of botulinum neurotoxin A other than SNAP-25. J Appl Toxicol, Vol.19, No.S1, pp. S27-28, ISSN 0260-437X

Razai, A., Garcia-Rodriguez, C. \& Lou, J. et al. (2005). Molecular evolution of antibody affinity for sensitive detection of botulinum neurotoxin type A. J Mol Biol, Vol.351, No.1, pp. 158-169, ISSN 0022-2836

Reames, H.R., Kadull, P.J. \& Housewright, R.D. (1946). Studies on botulinum toxoids types A and B III. Immunization of man. J of Immun, Vol.55, No.4, pp. 309-324, ISSN 00221767

Rotz, L.D., Khan, A.S. \& Lillibridge, S.R., et al. (2002) Public health assessment of potential biological terrorism agents. Emerg Inf Dis, Vol.8, No.2, pp. 225-230, ISSN 1080-6040

Roxas-Duncan, V., Enyedy, I. \& Montgomery, V.A., et al (2009). Identification and biochemical characterization of small-molecule inhibitors of Clostridium botulinum neurotoxin serotype A. Antimicrob Agents Chem, Vol.53, No.8, pp. 3478-3486, ISSN 0066-4804

Rubinson, L., Vaughn, F. \& Nelson, S. (2010). Mechanical ventilators in US acute care hospitals. Dis Med Pub Health Prep, Vol.4, No.3, pp. 199-206. ISSN 1935-7893

Rummel, A., Eichner, T. \& Weil, T. et al. (2007). Identification of the protein receptor binding site of botulinum neurotoxins $\mathrm{B}$ and $\mathrm{G}$ proves the double-receptor concept. PNAS, Vol.104, No.1, pp 359-364, ISSN 0027-8424

Rusnak, J.M. \& Smith, L.A. (2009). Botulinum neurotoxin vaccines. Past history and recent developments. Human vaccines, Vol.5, No.12, pp. 794-805, ISSN 1554-8600

Ryan, C.A., Nickels, M.K. \& Hargrett, N.T. et al. (1987). Massive outbreak of antimicrobial resistant salmonellosis traced to pasteurized milk. JAMA, Vol.285, No.2, pp.32693274, ISSN 0098-7484 
Sheridan R.E. (1996). Protonophore antagonism of botulinum toxin in mouse muscle. Toxicon, Vol.34, No.8, pp. 849-855, ISSN 0041-0101

Scott, A.B., \& Suzuki, D. (1988). Systemic toxicity of botulinum toxin by intramuscular injection in the monkey. Mov Dis, Vol.3, No.4, pp.333-335, ISSN 0885-3185

Sentinel laboratory guidelines for suspected agents of bioterrorism. Botulinum toxin. ASM, accessed 08/01/2011, http://www.asm.org/index.php/policy/sentinel-levelclinical-microbiology-laboratory-guidelines.html

Settler, P.E. (2001). Pharmacology of botulinum type B. Eur J Neurol, Vol.8, No.S4, pp. 9-12, ISSN 1351-5101

Shapiro, R.L., Hatheway, C. \& Becher, J. et al. (1997). Botulism surveillance and emergency response. A public health strategy for a global challenge. JAMA, Vol.278, No.5 pp. 433-435, ISSN 0098-7484

Shapiro, R.L., Hatheway, C. \& Swerdlow, M.D. (1998). Botulism in the United States: A clinical and epidemiological review. Ann Int Med, Vol.129, No.3, pp. 221-228, ISSN 0003-4819

Silhar, P., Capkova, K. \& Salzameda, N.T. (2010). Botulinum neurotoxin A protease: Discovery of natural product exosite inhibitors. J Am Chem Soc, Vol.132, No.9, pp. 2868-2869, ISSN 0002-7863

Sing, B.R., Thirunanvukkarasu, N., \& Ghosal, K., et al. (2010). Clostridial neurotoxins as a drug delivery vehicle targeting nervous system Biochimie, Vol.92, No.9, pp. 12521259, ISSN 0300-9084

Simpson L.L. (1982). The interaction between aminoquinoloines and presynaptically acting neurotoxins. J Pharmacol Exp Ther, Vol.222, No.1, pp. 43-48, ISSN 0022-3565

Simpson L.L. 1983. Ammonium chloride and methylamine hydrochloride antagonize clostridial neurotoxins. J Pharmacol Exp Ther, Vol.225, No.3, pp. 546-552, ISSN 00223565

Simpson L.L. (2004). Identification of the major steps in botulinum toxin action. Ann Rev Pharmacol Toxicol, Vol.44, pp. 167-193, ISSN 0362-1642

Sloop, R.R., Cole, B.A. \& Esculin, R.O. (1997). Human responses to botulism injection: type B compared to type A. Neurology, Vol.49, No.1, ISSN 0028-3878, pp. 189-194

Smith, L.A. (2009). Botulism and vaccines for its prevention. Vaccine, Vol.27, No.S4, pp. D33D39, ISSN 0264-410X

Smith L.D.S. \& Sugiyama, H. (1988). Botulism: The Organism, its Toxins, the Disease, (2nd ed.), Charles C. Thomas, ISBN 0398054460, Springfield, IL, USA

Smith, T.J., Lou, J. \& Geren, I.N. et al. (2005). Sequence variation within botulinum neurotoxin serotypes impacts antibody binding and neutralization. Infec and Imm, Vol.73, No.9, ISSN 0019-9567, pp. 5450-5457

Smith, T.J., Hill, K.K. \& Foley, B.T. et al. (2007). Analysis of the neurotoxin complex genes in Clostridium botulinum A1-A4 and B1 strains: BoNT/A3, /Ba4 and /B1 clusters are located within plasmids. PLosS One, Vol.2, No.12, pp.1-10, ISSN 1544-9173

Stringer, S.C., Webb, M.D. \& George, S.M. et al. (2005). Heterogeneityof times required for germination and outgrowth from single spores of nonproteolytic Clostridium botulinum. App Env Micro, Vol.71, No.9, ISSN 0099-2240, pp.4998-5003 
Sonnabend, O., Heinzle, R. \& Sigrist, T., et al. (1981). Isolation of Clostridium botulinum type $\mathrm{G}$ and identification of type $\mathrm{G}$ botulinal toxin in humans: report of five sudden unexpected deaths. J. Infect. Dis., Vol.143, No.1, ISSN 0022-1899, pp. 22-27

Sugishima, M. (2003). Aum Shinrikyo and the Japanese law on biotrerrorism. Prehospital and disaster medicine, Vol.18, No.3, pp.179-183, ISSN 1049-023X

Tacket, C.O., Shandera, W.X., \& Mann, J.M., (1984). Equine antitoxin use and other factors that predict outcome in type A foodborne botulism. Am J Med, Vol. 76, No. 5, pp. 794-798, ISSN 0002-9343.

Tang J.J., Park, G., \& Millard, C.B. et al. (2007). Computer-aided lead optimization: improved small-molecule inhibitor of the zinc endopeptidase of botulinum neurotoxin serotype A. PLoS ONE, Vol.2, No.8, pp. 2:e761, ISSN 1932-6203

Terranova, W., Palumbo, J.N. \& Breman, J. G. (1979). Ocular findings in botulism type B. JAMA, Vol.241, No.5, pp. 475-477, ISSN 0098-7484

Tremblay, J.M., Kuo, C.L. \& Abeijon, C. et al. (2010). Camelid single domain antibodies (VHHs) as neuronal cell intrabody binding agents and inhibitors of Clostridium botulinum neurotoxin (BoNT) proteases. Toxicon, Vol.56, No.6, pp. 990-998, ISSN 0041-0101

United Nations Security Council. (1995). Tenth report of the executive chairman of the special commissions established by the secretary-general pursuant to paragraph 9(b)(I) of security council resolution 687 (1991) and paragraph 3 of resolution 699 (1991) on the activities of the special commission. New York, pp.S/1995/1038.

Varma, J.K., Katsitadze, G., \& Moiscrafishvili, M. et al. (2004). Signs and symptoms predictive of death in patients with foodborne botulism-Republic of Georgia, 19802002. Clin Infect Dis, Vol.39, No.33, pp.357-362, ISSN 1058-4838

Wannemacher, R.W., Dinterman, R.E., \& Thompson, W.L. et al. (1993) Treatment for removal of biotoxins from drinking water. Technical report 9120. U.S. Army Biomedical Research and Development Laboratory, Fort Detrick, Frederick, Md.

Wein, L.M. \& Liu, Y. (2005) Analyzing a bioterror attack on the food supply: The case of botulinum toxin in milk. PNAS, Vol.102, No.28, pp. 9984-9899, ISSN, 0027-8424

Webb, R.P., Smith, T.J. \& Wright, P. et al. (2009). Production of catalytically inactive BoNT/A1 holoprotein and comparison with BoNT/A1 subunit vaccines against toxin subtypes A1, A2, and A3. Vaccine, Vol.27, No.33, pp. 4490-4497, ISSN 0264$410 \mathrm{X}$

Woodruff, B.A., Griffin, P.M. \& McCroskey L.M. (1992). Clinical and laboratory comparison of botulism from toxin types A, B, and E in the United States, 1975-1988. J Infect Dis, Vol.166, No.6, pp. 1281-12866, ISSN 0022-1899

Williams, P. \& Wallace, D. (1989). Unit 731: Japan's Secret Biological Warfare in World War II. The Free Press, ISBN 0029353017, New York, NY, USA.

Yang, Y., Lindo, P. \& Riding, S. et al. (2008). Expression, purification and comparative characterization of enzymatically deactivated recombinant botulinum neurotoxin type A. Botulinum Vol.1, No.2, pp. 219-241, ISSN 1754-7318

Yuan, J., Inami, G., \& Mohle-Boetani, J. (2011) Recurrent wound botulism among injection drug users in California. Clin Infec Dis, Vol.52, No.7, pp. 862-866, ISSN 1058-4838

Zhang, P., Ray, R., \& Sing, B.R., et al. (2009) An efficient drug delivery vehicle for botulism countermeasure. BMC Pharm, Vol.9, No.12, pp. 1-9, ISSN 1471-2210 
Zilinkas, R.A. (1997). Iraq's biological weapons: the past as future? JAMA, Vol.278, No.5, pp. 418-424, ISSN 0098-7484 


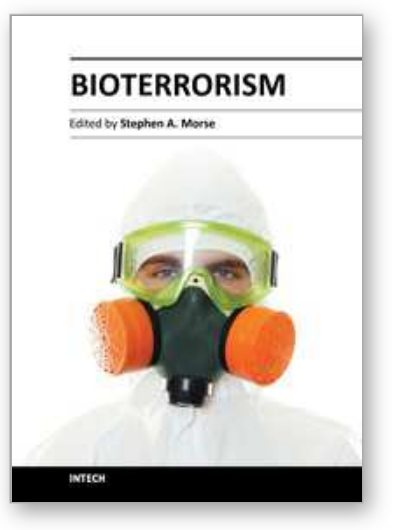

\author{
Bioterrorism \\ Edited by Dr. Stephen Morse
}

ISBN 978-953-51-0205-2

Hard cover, 192 pages

Publisher InTech

Published online 28, March, 2012

Published in print edition March, 2012

This book consists of nine chapters, written by international authorities, discussing various aspects of bioterrorism preparedness and response. Five of the chapters are agent-specific and highlight the pathogenesis, prevention and treatment, and the potential of specific organisms (Rickettsia and Yersinia pestis) or toxins (ricin, botulinum neurotoxins, and staphylococcal enterotoxins) to be used for nefarious purposes. Four chapters discuss different aspects of detecting and responding to a bioterrorism attack. These include methods for spatio-temporal disease surveillance, international laboratory response strategies, detection of botulinum neurotoxins in food and other matrices, and the use of physical methods (ie Raman spectroscopy) to detect spores.

\title{
How to reference
}

In order to correctly reference this scholarly work, feel free to copy and paste the following:

Robert P. Webb, Virginia I. Roxas-Duncan and Leonard A. Smith (2012). Botulinum Neurotoxins, Bioterrorism, Dr. Stephen Morse (Ed.), ISBN: 978-953-51-0205-2, InTech, Available from:

http://www.intechopen.com/books/bioterrorism/botulinum-neurotoxins1

\section{INTECH}

open science | open minds

\section{InTech Europe}

University Campus STeP Ri Slavka Krautzeka 83/A 51000 Rijeka, Croatia Phone: +385 (51) 770447

Fax: +385 (51) 686166 www.intechopen.com

\section{InTech China}

Unit 405, Office Block, Hotel Equatorial Shanghai No.65, Yan An Road (West), Shanghai, 200040, China 中国上海市延安西路65号上海国际贵都大饭店办公楼405单元 Phone: +86-21-62489820

Fax: $+86-21-62489821$ 
(C) 2012 The Author(s). Licensee IntechOpen. This is an open access article distributed under the terms of the Creative Commons Attribution 3.0 License, which permits unrestricted use, distribution, and reproduction in any medium, provided the original work is properly cited. 